José María Alberdi

Mag. en Servicio Social.

Docente de la Escuela de Trabajo Social (UNR). Centro Regional de Salud Mental "Dr. Agudo Avila".

E-mail:jmalberdi68@hotmail.com

\title{
Entre la codificación de los comportamientos bizarros $y$ el elogio de la locura
}

\begin{abstract}
Resumen
Este artículo presenta una perspectiva de lectura de la codificación de los comportamientos bizarros y el elogio de la locura en las nuevas instituciones psiquiátricas. A partir del abordaje de algunas escenas institucionales plantea las tensiones y dilemas presentes en los usos de la civilidad en las formas del tratamiento de la locura,
\end{abstract}

teniendo especialmente en cuenta los aportes de Norbert Elias y George Vigarello. En las conclusiones se revisan las aporias de la psiquiatría tradicional y alternativa en sus tareas de tratar y «civilizar» a los locos de los sectores populares.

\section{Palabras claves}

locura $\cdot$ comportamiento bizarro

«....No soy tan ingenuo y utopista para creer que existiría una metodología analítica segura que erradicase en profundidad todos los fantasmas que conducen a reíficar a la mujer, al inmigrante, al

loco, etc. y eliminase las instituciones penitenciarias, psiquiátricas etc. Pero me parece que una generalización de las experiencias de análisis institucional (en el hospital, en la escuela, en el medio urbano) podría modificar profundamente los datos de este problema...»

Félix Guattarí, Las Tres Ecologías

\section{Introducción}

Este ejercicio narrativo parte de la posibilidad de un diálogo entre algunas escenas institucionales ${ }^{1}$ producidas en un manicomio rosarino y sus afinidades electivas con el problema de ciertas historias del pudor y el comportamiento, mostrando la ambigüedad y la tensión presentes en los usos del cuerpo, en sintonía con la gradual pacificación de las costumbres y las transformaciones de la agresividad en la cultura de estas instituciones.

Una de las palabras claves que pueden servir de disparador para obligar a una primera condensación, pero también a cierta apertura, es la sorpresa ciertamente paradojal de encontrar en distintos espacios de esta institución moderna el uso de lo bizarro como adjetivo que califica distintas lecturas de la locura.

Una primera escena -la más típica-: la redacción de un Comité de Admisión posterior a una entrevista con un paciente «involuntario», en la cual el concepto

\footnotetext{
${ }^{1}$ Escenas institucionales que no deben ser tomadas al pie de la letra, algunas fueron observadas, otras comentadas, otras forzadas. En este punto, como la literatura de no ficción, debe encontrar como límite lo selectivo de cualquier memoria o ejercicio testimonial. Punto de fuga más que punto de entrada para la comprensión de la actualidad de ciertas culturas institucionales. Escenas institucionales en que trataremos de respetar el mandato spinoziano: «no lamentar, no reír, no detestar, sino comprender». Una advertencia: este trabajo no tiene nada de novedoso, sólo se suma de forma «bizarra» a las tradiciones de la antipsiquiatría y la sociología crítica.
} 
de comportamiento bizarro ${ }^{2}$ ayuda a sintetizar toda una serie de comportamientos marcados por la extravagancia (desde la desnudez a la errancia, desde la molestia persistente a los vecinos hasta la anulación en el encierro de la pieza familiar, desde la transgresión a la normas de urbanidad hasta las risas «inmotivadas») y que quedan por fuera de los compartamientos más asociados al pasaje al acto -dicho en los conceptos reguladores del psicoanálisis- o la terminología más peligrosista de «agresivo para sí o para terceros».

Una segunda escena, observada en la presentación de pinturas y comics de pacientes de un Área Cultural, en que entre analistas de diversas disciplinas se discurría sobre las relaciones entre el arte bizarro, o inclusive el arte bruto, y las producciones de los pacientes. Lo raro, lo extravagante, lo fenomenal, se convierte en materia prima de un nuevo ensayo de la vieja historia entre locura y arte, obras que de tan malas (como las de Ed Wood) pueden llegar a ser buenas.

Evidentemente ambas escenas marcan lo bizarro como elemento para diagnosticar una cierta situación, diagnóstico médico por un lado, diagnóstico cultural por el otro; uno más marcado por la codificación de los comportamientos, otro más preocupado por cierto elogio de la locura y un ejercicio de la tolerancia y el pluralismo cultural, pero entre ellos cierta des-conexión naturalizada en los manicomios líquidos.

Otra escena institucional, referida a imágenes asociadas al pudor y a lo limpio y lo sucio, y el problema del olor «manicomial»: el equipo interdisciplinario se reúne con los jefes de enfermería para repasar el report y las principales conductas y faltas a los reglamentos médicos y a las pautas de convivencia institucional de los pacientes. En medio del pase, irrumpe una paciente de largo aliento en la institución, que lleva varios días sin bañarse y sin «controlar esfínteres». Exige cigarrillos, observándose todo tipo de transacciones, en las que emergen distintas posturas evitativas del contacto y diversas formas de negociación: desde gestos de tapar la nariz hasta luchas cuerpo a cuerpo por el retiro de la paciente, desde quejas sobre la desidia de enfermería hasta guardar los cigarrillos de forma imperiosa para no ser pillados en el acto; el pudor, la vergüenza y la repugnancia se dan cita sin demasiado disimulo, en medio de risas nerviosas ${ }^{3}$.

\footnotetext{
${ }^{2}$ Comportamiento bizarro que en los tratados de psiquiatría, como los de Henri Ey, es reconocido también con los nombres de discordancia o extravagancia, siendo definido clásicamente como «...una distorsión de la vida psíquica, cuya pérdida de la unidad, incomodidad y malestar conducen a rodeos extraños o fantásticos que dan la impresión de una búsqueda barroca, de una serie de paradojas encadenadas caprichosamente...» (1965: 507). Jaspers, desde su fenomenología interpretativa, se planteaba: «...al interrogante de cuánto y por qué son anormales los caracteres, no hay ninguna respuesta posible. Tenemos que estar conscientes que lo anormal dicho en general no es una comprobación efectiva sino una valoración» (1913: 97). Cuestión que no es debidamente tenida en cuenta ya que, como refieren los psiquiatras de escuela, aquello que sale de lo normal y que se aparta de las convenciones sociales y culturales es fundamental a la hora de diagnosticar un desorden mental.

${ }^{3}$ Como señala Norbert Elias, autor que iluminara buena parte de estas reflexiones, este tipo de situaciones cotidianas encierran toda una serie de paradojas: «...No carece de interés observar que, una vez se ha consolidado una cierta apertura en relación al siglo XIX, al menos en lo que respecta a la posibilidad de hablar de las necesidades corporales. La libertad y el desenfado con los que hoy se dice lo que hay que decir, y además, sin desconcierto, sin la sonrisa reprimida y las risitas de infracción al tabú, resultan evidentes en la post-guerra. Pero al igual que en las costumbres de baño y de danza de la época contemporánea, todo esto es posible porque en líneas generales, se ha asegurado la pauta de las costumbres, las autocoacciones técnico-institucionales, así como el grado de represión de la propia vida impulsiva y del propio comportamiento. Se trata por tanto de una abertura en el marco de una pauta de comportamiento ya establecida...» (1993: 181).
} 
Finalmente, una última escena, con varios elementos tragicómicos, pero primero una introducción con el uso feudal del recurso de autoridad. Refiere E. Zaffaroni -en el prólogo a un reciente libro de E. Galende- sobre las lecciones brindadas por un paciente en medio de un congreso de psiquiatría alternativa: «Otra lección inolvidable la recibimos de un paciente, el Güero, que era un hombre joven, bastante comunicativo y simpático, que nos compraba cigarrillos y hacía mandados, llevaba tiempo de internación y un buen día, fue dado de alta. A los pocos días volvió y cuando le preguntamos por qué nos dijo, para nuestro asombro, que había vuelto porque afuera no hay libertad. Le pedimos que nos explicara un poco más y precisó: Es claro. Aquí si quiero me desnudo y no pasa nada. En mi casa, me subí a la azotea, me desnudé y las vecinas hicieron un escándalo, Ilamaron a la policía....No hay libertad allá...» (2006:14).

Siguiendo ahora sí con nuestras escenas y trayendo otro ejemplo -bizarrosobre el tratamiento de la desnudez en el manicomio, se chocan dos terapeutas frente a la escena de desnudez que cada tanto exhibe una anciana de uno de los pabellones, la psicoanalista devenida tallerista plantea, casi escandalizada, que en el hospital a esta hora (por la tarde) está todo naturalizado, es «tierra de nadie». El otro, más antipsiquiatra, le contesta: «lo de Mafalda es una forma de protesta cuando está enojada». Ambos siguen con sus respectivas tareas ante la mirada extrañada de una enfermera (y tal vez de la propia paciente). A continuación llegará el médico de guardia con el SOS y si esta conducta persiste restablecerá las buenas costumbres.

Escenas arbitrarias, se dirá, escenas del día a día de una institución psiquiátrica y sus reformas permitidas. Sin embargo, se considera que una lectura polifónica de la evolución de los buenos modales, o de la propia historia de la limpieza y su relación con los comportamientos, puede ayudar a comprender parte de las encerronas de estas instituciones dedicadas al cuidado y al asilo de las personas locas y a interpelar las distintas pedagogías de la sociabilidad presentes en las versiones del viejo y nuevo higienismo médico, así como de las alternativas que trabajan en torno de un «otro» lugar social para la locura.

Escenas que también promueven un diálogo, en el que consideramos necesario tematizar y poner en discusión uno de los planteos fuertes de Gauchet y Swain, quienes referirían en su trabajo (el otro de Foucault): «...en la Edad Media había con el loco una proximidad de hecho, más una distancia absoluta de derecho, en la época moderna, por el contrario, la identidad es de derecho y la distancia de hecho...» (1980: 12).

Es decir, nos interesa trabajar sobre esa distancia de hecho, teniendo más en cuenta las lecturas de Elías y Vigarello, en el sentido de cuánto peso tienen en las distancias de hecho lo que cínicamente podríamos denominar como crónicos problemas de etiqueta; falta de compostura y buenos modales que afectan la vida diaria de las personas locas de los sectores populares, tendiendo un primer puente de sociología del detalle con esto que la psiquiatría clásica denominó como comportamiento bizarro o, más tempranamente, como extravagancia. Y también, por qué no, revisar algunas de las formas clandestinas de pedagogía de los comportamientos presentes en las instituciones psiquiátricas en tiempos de «desregulación» de los comportamientos, relativización de las normas e individualización.

Distancia de hecho, en que nuestra hipótesis es marcar otro tipo de distancia antropológica donde las exclusiones de hecho no se verifican tanto en el 
plano de la exclusión legal o en el plano de la exclusión institucional, sino que en parte son algunas de las consecuencias de los usos de la civilidad en los locos y sus comportamientos extravagantes. Tanto en los esfuerzos de codificación y control de los comportamientos para la sociedad en general y en los efectos de difusión-dominación en las distintas clases sociales. En particular, las y los locos por sus excentricidades y bizarría quedaron especialmente sujetos a las normas de urbanidad, a las exigencias de ciertas formas de comportamiento que los expondrían tempranamente a la sanción del grupo y de la comunidad de «pertenencia».

\section{Transformación de los comportamientos, civilización y barbarie}

Norbert Elías, haciendo un uso amateur de la lectura de sus trabajos, confiere especial importancia a las transformaciones y los cambios en las reglas del buen vivir. En su clásico texto El proceso de civilización analiza desde una historia del presente cómo las normas de urbanidad, los buenos modales, regulan -en sintonía con una dinámica en tensión evolutiva- numerosas áreas de la vida social, constituyendo las bases en donde se asientan el pudor y la vergüenza en la construcción de la intimidad moderna y, paralelamente, cómo contribuyeron a modelar las actitudes, valores y comportamientos, en la interiorización de las normas y en la estructura de la personalidad.

Entre una serie de demostraciones, su trabajo con materiales históricos permitió plantear cómo para la emergencia y el desarrollo de las sociedades modernas era necesaria la formación de un tipo particular de personalidad, en analogía con los cambios en la paradojal pacificación de las formas de funcionamiento del poder y el control social en la versión occidental.

Retomemos algunos temas de su trabajo, entre ellos los que permiten su re-lectura de la colección popular de Erasmo de Rótterdam sobre las recomendaciones doctrinarias al príncipe de las conductas en sociedad y el decoro externo del cuerpo. Texto de transición que acompaña la promoción de una nueva pedagogía popular en la definición de los criterios empleados para determinar si un comportamiento es malo, bueno o mejor que otro, pero también texto dedicado a un príncipe que, como en Maquiavelo, debe asegurar su distinción, las posibilidades de propiedad y de prestigio que lo diferencian de los grupos inferiores.

Si el texto de Maquiavelo se dirigía al príncipe en el sentido de asegurar su gobernabilidad con mayúsculas, el texto de Erasmo ayuda a pensar en el gobierno de las costumbres y en la promoción gradual de una nueva economía afectiva, marcada por la moderación de los impulsos, la constitución gradual de coacciones internas en el entramado de la personalidad y en el límite de los escrúpulos.

Texto y textos de esa curva civilizatoria, que pueden devolver cierta inteligibilidad a partes de las preocupaciones presentadas en algunas de las escenas institucionales, si entendemos también que la psiquiatría hasta hace muy poco tiempo era asociada a una ciencia de los comportamientos. En el texto de Erasmo, las recomendaciones sobre las buenas costumbres participan de una sociología del detalle que prepara al príncipe -y no sólo a él- en el desarrollo de los buenos modales, la actitud corporal, los ademanes, la vestimenta, el 
decoro en la mesa, las formas de sonarse la nariz, la cortesía en el trato. Revisemos algunas de las enseñanzas, no dejando de lado algunas de las escenas sobre el comportamiento socialmente aceptable en las cortes:

«...los ojos muy abiertos son un signo de estupidez, la mirada fija es un símbolo de indolencia, la mirada muy penetrante indica una propensión a la ira, los desvergonzados tienen una mirada muy viva y muy elocuente; lo mejor es que la mirada muestre un ánimo reposado y una amistad respetuosa...».

«...Escupe haciéndote a un lado para no ensuciar o rociar a nadie. Si cayera al suelo algo purulento, hay que eliminarlo con el pie, para que nadie sienta repugnancia. Si ello no fuera posible, sírvete de un pañuelo...».

«...Es conveniente que se hagan pausas durante la comida por medio de una conversación interesante. Algunos comen y beben sin parar, no porque tengan hambre y sed, sino porque no saben dominarse de otro modo y tienen que estar rascándose la cabeza, hurgando entre los dientes, gesticulando con las manos o jugando con el cuchillo; o bien tosiendo, resoplando, escupiendo. En realidad, todo esto muestra la incomodidad que siente el aldeano y da la impresión de tratarse de una especie de locura...».

«...no te desnudes si no hay necesidad, descubrir sin necesidad los miembros velados al pudor debe ser contrario al buen carácter y si la necesidad obliga a ello, hay que hacerlo con sumo recato...».

«...retener un pedo producido por la naturaleza es cosa de necios, que conceden mayor importancia a la educación que a la salud, cuando hayas de vomitar apártate, que no es feo vomitar, pero si forzarse el vómito...».

«...es vergonzoso para quienes son de noble cuna no tener la buena conducta que corresponde a su nueva extracción. Aquellos a quienes la fortuna ha hecho plebeyos, personas de humilde condición, hasta campesinos, han de esforzarse tanto más en compensar mediante buenos modales las ventajas que les negó el azar. Nadie elige su país ni a su padre: todo el mundo puede adquirir buen modo y conducta...»(Erasmo, 1529: 33 apud Elías, 1989).

Sin embargo, como refiere Elías, el mismo texto genera cierto malestar y cierta repugnancia en su lectura actualizada: «...El malestar mayor o menor que produce en nosotros las personas que mencionan o hablan abiertamente de sus funciones corporales o que ocultan o reprimen menos que nosotros tales funciones es una de las sensaciones dominantes que se expresan en los juicios de 'bárbaro' o incivilizado. Tal es por lo tanto el «malestar de la barbarie» o, por decirlo de algún modo algo más neutral, el malestar que produce aquella otra constitución emotiva, aquella otra pauta de pudor que hoy se encuentra en muchas sociedades a las que llamamos «incivilizadas», el malestar que precedió a la nuestra y que es su presupuesto...» (1989: 223).

Texto humanista y en un punto renacentista que, entre reformas, le permite a Elías leer en simultáneo las transformaciones de la sociedad y los comportamientos, en donde una sociedad caballeresco-feudal entra en crisis mientras la nueva cortesano-absolutista se está gestando, pero que en un largo trabajo de la historia tendrá su peso en la constitución de la individualidad moderna.

Y le permite leer, sobre todo, la constitución de esa segunda naturaleza, ese inconsciente colectivo, social e histórico, que también podría ser pensado como una historia del peso gradual del pudor y la vergüenza y de las transformaciones graduales entre lo público y lo privado en la transición a la modernidad, con 
particular implicación para la cercanía de derecho y la distancia absoluta de hecho que venimos trabajando en relación a la locura. Como refiere en una cuidadosa síntesis compleja Jacques Revel: «...Norbert Elías fue el primero en mostrar hace ahora medio siglo que esta imposición multiforme descansaba en las presiones que ejercía el grupo, de arriba abajo, sobre cada individuo, y también cada vez más, en la incorporación de las reglas sociales por cada cual. La socialización de las conductas no puede leerse sólo como una sumisión impuesta a las personas, pues no alcanza plenamente sus fines más que cuando cada cual se aplica en tratar de ser su propio dueño, como aconsejan tantos textos antiguos y llega a considerar la norma como segunda naturaleza o, mejor, como la verdadera naturaleza, por fin recobrada. En suma, ese trabajo de la sociedad en relación consigo misma se efectúa en dos direcciones, que son en apariencia contradictorias, pero cuyos efectos tienen el mismo sentido. Los tratados de civilidad tienen por objeto crear entre los hombres las condiciones de un trato agradable, lícito y cada vez más conforme a las exigencias reforzadas de la religión. Por consiguiente, imponen a sus lectores comportamientos que cumplan las reglas de una sociabilidad que cada vez se vuelve más imperativa y más insinuante. Casi puede decirse que llevan al extremo la lógica erasmiana situando todo acto individual ante la mirada de todos, pero al mismo tiempo invitan a cada persona a separar en sí misma lo que es mostrable (civil y por lo tanto bueno) de lo que todos, y hasta ella deben ignorar. El espacio individual es invadido por el control colectivo y, a la vez, confinado en el vergonzoso silencio de las prohibiciones. Sin embargo, sería engañoso separar muy claramente los dos aspectos de esta evolución: son como la cara y la cruz de una misma historia social de las sensibilidades...» (1991: 184).

Es esta segunda naturaleza, volviendo a uno de los tópicos centrales de nuestro ejercicio, esta proscripción social más intensa de muchas manifestaciones de los impulsos y con su exclusión de la superficie (especialmente de la vida social), la que va a generar una barrera cultural entre el comportamiento y la estructura psíquica consideradas socialmente normales y el comportamiento «bizarro» de los afectados por la locura, comprendiendo en parte las posturas cotidianas de rechazo y baja tolerancia hacia la locura, en su particular juego de poner en crisis las relaciones entre lo público y lo privado en las acciones cotidianas.

Norbert Elias alertaba especialmente sobre estas cuestiones, hace más de sesenta años, y al mismo tiempo hacía justicia a Freud4: «En cierto sentido, es muy ilustrativo aquí el final del texto D: 'mucho menos se debe mostrar cosas fétidas para que las huelan, como suelen hacer algunos con gran inoportunidad, etc...'. Un carácter y un comportamiento de este tipo, en la pauta actual de

${ }^{4}$ Justicia a Freud, pero paralelamente distanciamiento, en especial al demostrar que la nueva economía psíquica que se va desarrollando con la «pacificación» de las costumbres y la interiorización de las prohibiciones y los autocontroles, es social e histórica y no estructural o universalmente válida. Como revisa Roger Chartier, este es uno de los nudos centrales de la obra de Elías: «A medida que va diferenciándose el tejido social, el mecanismo genético del autocontrol psíquico evoluciona hacia una diferenciación, una universalidad y una establidad más grandes. La estabilidad particular de los mecanismos de autocoacción psíquica que constituye el rasgo típico del hombre «civilizado» está estrechamente ligada a la monopolización de la coacción psíquica y a la solidez creciente de los órganos sociales centrales. La formación de monopolios es precisamente lo que permite la puesta en marcha de un mecanismo de «acondicionamiento social» gracias al cual se educa cada individuo en un riguroso autocontrol. Este es el origen del mecanismo de autocontrol individual permanente cuyo funcionamiento es en parte automático ...» (1995: 97). 
los sentimientos de pudor y de escrúpulos y de acuerdo con el esquema de dominio de las emociones que hoy impera, calificaría a una persona sin más, como enferma, patológica, perversa. Cuando la inclinación a este tipo de comportamientos comenzara a hacerse pública, quien la tuviera sería recluido en la casa o bien encerrado en un sanatorio. Si este carácter solamente se manifestara entre bastidores de la vida social, recaería sobre el alienista la labor de corregir el mal condicionamiento de esta persona. Por regla general, los impulsos han desaparecido de la conciencia cotidiana de los adultos bajo la presión del condicionamiento social. Tan sólo el psicoanálisis es capaz de descubrirlos bajo la forma de inclinaciones irrealizadas e irrealizables, a las que suele designarse como subconsciente o elemento onírico...» (1993: 183).

\section{Civilizar a los locos: ¿tarea de la psiquiatría?}

Volviendo a la historia de la locura, podemos recordar las «virtudes» y hasta cierta «necesidad» del tratamiento moral en su tarea de civilizar a los locos, forma en que Pinel ya nombraba su tecnología de disciplinamiento, pero también de retorno a la ciudadanía del loco a la vida normal, en tanto se sometiera a la conformación socialmente exigida del comportamiento -si no probablemente quedaría excluido de la vida en la sociedad «moralizada»-. Tratamiento moral que se presentaba fundamentalmente como una pedagogía de los comportamientos: en un solo tiempo lo pedagógico y lo terapéutico se aunaban en la rehabilitación del ciudadano. Medicalización de los comportamientos, en que la locura era producto de la sociedad y de las influencias morales e intelectuales.

En cierto modo, entre las principales causas de la locura y de la alienación mental, recordemos que las más importantes en la literatura de Pinel referían a las pasiones intensas y prolongadas, a las irregularidades y las transgresiones de las costumbres y los hábitos de vida, a las conductas desconocedoras de la sensibilidad física y moral, que eran mostradas y mensuradas en forma distintiva en el estudio de los aspectos exteriores de los enfermos mentales ${ }^{5}$.

Por lo tanto, el asilo se constituirá para Pinel en el lugar donde se desarrollará por largo tiempo ese laboratorio correccional, el aislamiento terapéutico, una construcción pineliana que hasta los días actuales no está totalmente superada. Una de las razones principales es que las causas de la alienación mental están presentes en su medio social y el aislamiento es una forma que permitirá apartarlas. El propio Pinel explica y justifica tal proceso: «...En general, es tan agradable para un enfermo estar en el seno de la familia y ahí recibir los cuidados y los consuelos de una amistad tierna e indulgente, que enuncio penosamente una verdad triste, mas constatada por la experiencia repetida, cual es sino, la absoluta necesidad de confiar los alienados a manos extranjeras y de aislarlos de sus parientes. Las ideas confusas y tumultuosas que los agitan son provocadas por todo lo que los rodea, su irratibilidad continuamente

\footnotetext{
${ }^{5}$ La locura se irá reconociendo como pasaje de la moral desbordada al trastorno mental, el pasaje de las pasiones excesivas a los lenguajes de la psiquiatría; antes una conciencia desgraciada, ahora una disociación de la mente; pasaje también de la locura como arte de la simulación, como gran mercado de actuación, como lo que atrae por los excesos o los defectos en los usos públicos o privados de sus pasiones sombrías e «irracionales».
} 
provocada por objetos imaginarios, gritos, amenazas, escenas de desorden o actos extravagantes; el empleo juicioso de una represión enérgica, una vigilancia rigurosa sobre el personal de servicio cuya grosería e impericia también se debe temer, exigen un conjunto de medidas adaptadas al carácter particular de esta enfermedad, que sólo pueden ser reunidas en un establecimiento que a ellos les sea consagrados...» (Pinel, 1801: 123 apud Castel, 1978: 87).

Y en su discípulo Esquirol (1838 apud Foucault, 1979:126) encontraremos las principales razones para una justificación política del aislamiento, notando entre las principales: garantizar la seguridad personal del loco y sus familias, liberarlos de las influencias externas, vencer sus resistencias personales, someterlos a un régimen médico e imponerles nuevos hábitos intelectuales y morales.

Entre las formas de tratamiento moral, que fueron evolucionando en el tiempo para el loco -enclausurado-, podemos recordar algunas de las pinturas foucaultianas, como la considerada en un punto genética en sus clases sobre el poder psiquiátrico. Allí se registra el pasaje del poder soberano al poder disciplinar, el caso de la escena de curación de Jorge III que el texto de Pinel relata de esta forma: «Un monarca cae en la manía y para que su curación sea más rápida y sólida, no se pone ninguna restricción a las medidas de prudencia de quien lo dirige; por ello todo el aparato de la realeza se desvanece, el alienado, alejado de su familia y de todo lo que lo rodea, queda confinado en un espacio aislado y se lo encierra solo en una recamara cuyos cristales y muros se cubren de colchones para impedir que se hiera. Quien dirige el tratamiento le informa que ya no es soberano y le advierte que en lo sucesivo debe mostrarse dócil y sumiso. Dos de sus antiguos pajes, de una estatura hercúlea, quedan a cargo de atender sus necesidades y prestarle todos los servicios que su estado exige, pero también de convencerlo de que se encuentra bajo su entera dependencia y de que allí en más debe obedecerlos. Guardan con él un tranquilo silencio, pero en cuanta oportunidad se les presenta le hacen sentir la superioridad de su fuerza. Un día, el alienado, en su fogoso delirio, recibe con mucha dureza a su antiguo médico durante su visita, lo embadurna con suciedades y basura. Uno de los pajes entra al punto a la recámara sin decir una palabra, toma por la cintura al delirante, también reducido a un estado de mugre repugnante, lo arroja con vigor sobre un montón de colchones, lo desviste, lo lava con una esponja, le cambia la ropa y, mirándolo con altivez, sale deprisa para retomar su puesto. Lecciones similares, reiteradas a intervalos durante algunos meses y secundadas por otros medios de tratamiento, han producido una curación sólida y sin recaídas...» (Pinel, 1801: 176 apud Foucault, 2005: 40).

No seguiremos todos las pistas de Foucault en la lectura de la escena, sólo nos detendremos en algunas que alimentan algunas continuidades con el motivo de este texto. Entre ellas, el pasaje de un poder soberano a un poder discreto, repartido. Según Foucault, es un poder que funciona en red y cuya visibilidad sólo radica en la docilidad y la sumisión de aquellos sobre quienes se ejerce en silencio. Poder disciplinario que despega también como dictadura de las necesidades «...en la relación de disciplina que vemos aparecer enseguida, no está en modo alguno al servicio de la voluntad del rey, y si se atiende las necesidades de éste no lo hace porque tal sea la voluntad del monarca; está al servicio de las necesidades y el estado del rey sin que intervengan ni la voluntad ni el estatuto del soberano, sólo las exigencias en cierto modo mecá- 
nicas del cuerpo fijan y determinan el carácter del servicio prestado por el servidor. Desconexión, por consiguiente, entre la voluntad y la necesidad, el estatuto y el estado. Y el servidor sólo intervendrá como fuerza de represión, sólo abandonará el servicio para convertirse en obstáculo a la voluntad del rey, cuando se exprese por encima de sus necesidades, por encima de su estado...» (2005: 41).

Poder disciplinario en que las resistencias partirán del desecho, el excremento y la basura, como dice lúcidamente Foucault: el monarca ha reemplazado su cetro y su espada por sus inmundicias, que por otro lado retoma un gesto secular de la insurrección contra los poderosos, de los más pobres, de los que no tenían nada. Inversión del poder, que también retorna como desplazamiento, mientras quien atentara contra la soberanía, le arrojara piedras e inmundicias, habría sido ahorcado y ejecutado según la ley inglesa, la disciplina que interviene ahora encarnada en el paje va, al contrario, a derribar, desnudar, lavar, hacer del cuerpo algo limpio y verdadero al mismo tiempo...» (2005: 43).

Disciplina preocupada por desnudar, lavar, hacer del cuerpo algo limpio, parte de las tareas de la psiquiatría casi desde su constitución, pero no sólo de la psiquiatría. Como George Vigarello nos orienta, la higiene del cuerpo desde la Edad Media se constituyó a la vez en una historia política y médica. Las evoluciones que sufre la limpieza corporal muestran pasados de diferente extensión: si sobre el final de la Edad Media el aseo debía ser seco, es decir se concentraba sobre lo visible y se identificaba con enjuagarse y perfumarse, es con la transición a la modernidad que el agua vuelve a ser jerarquizada entre las principales técnicas de limpieza y forma parte de una nueva imagen del cuerpo que excede el terreno de las buenas costumbres. La higiene rehabilita la intimidad corporal y legitima la búsqueda de utilización mejor de los recursos orgánicos. Se incluye en la medicina y luego en la escuela y pronto llega a ser el dispositivo de una nueva forma de control colectivo de los comportamientos.

¿Por qué nos interesa esta evolución? Primero porque las preocupaciones con respecto a la limpieza se imponen gradualmente a través de varios tipos de discursos y prácticas.

Segundo, porque da muestras de una nueva sensibilidad, en que el higienismo en general y el alienismo en particular, en sus formas policiales y filantrópicas, participarán institucionalmente de lo que Vigarello denomina «pastoral de la miseria»: «...En realidad, la imagen del pobre y sobre todo, la de la miseria están cambiando y convirtiéndose en algo más inquietante y más amenazador con la nueva ciudad industrial, igual que va cambiando la 'pedagogía' destinada a los indigentes y el lugar que van ocupando las prácticas de limpieza. Finalmente se va imponiendo con insistencia desconocida hasta ese momento una asociación: la limpieza del pobre se convierte en garantía de moralidad que, a su vez, es garantía de orden... Miseria inquietante cuyos harapos y piojos son signos de un ilegalismo siempre posible y de una delincuencia por lo menos latente... Si el hombre se habitúa a los andrajos, pierde inevitablemente el sentimiento de dignidad y cuando este sentimiento se ha perdido, queda la puerta abierta a todos los vicios» (1991: 241).

Tercero, porque el higienismo y el alienismo serán acompañados por la pedagogía en la administración de los peligros sanitarios, políticos y sociales: «...París alimentaba en su seno salvajes de nuevo tipo» (1991: 281). Pedagogías que para los sectores populares instalarán con la limpieza una nueva 
economía moral, en donde los manuales de higiene se confirman como textos pedagógicos, pero que se encerrarán fundamentalmente en soluciones morales, ya que el acceso a la limpieza, al baño y a la intimidad es una propiedad de la burguesía. Como refiere Vigarello, el acceso a la limpieza para los sectores populares, exige, además de recursos, austeridad y control: «...La difusión en los otros grupos sociales es muy diferente. La norma toma en ellos ciertas vías autoritarias: no se trata del acceso a un espacio íntimo en que la exigencia interior de limpieza va introduciendo sentimientos de seguridad y placer, sino la insistencia pedagógica que debe llevar a que un pueblo adopte referencias que otros han ido adquiriendo. El principio de la 'trasmisión' no es nuevo, como nos lo muestra la pastoral de la miseria, a mediados del siglo XIX. Pero la austeridad de las precauciones pasteurianas, la transformación de los circuitos de agua, la diversificación de los aparatos, cambian las condiciones mismas de esa trasmisión. El efecto que se espera de las limpiezas populares tampoco es nuevo: orden y salud...» (1991: 273).

Este acompañamiento entre pedagogía, costumbres y medicinas, no supone la típica pretensión científica de generar una ruptura con las costumbres sino que, como en otras partes, la medicina asegura y es una nueva fuente de legitimidad para la evolución de las mismas. En el texto que estamos citando, Vigarello se lo pregunta de forma «epistemológica»: «...Este exceso -el de la exigencia de la higiene que tomó formas catastróficas en los hijos de Pasteur-, claro está se ha puesto al servicio de una retórica, hay que convencer. Pero hay otras causas. ¿Por qué la limpieza recibe tan 'fácilmente' un nuevo papel (el de apuntalar una energía inmunizante después de relativizar el peligro inmediato del microbio)? ¿Por qué tenemos esta propensión a emplear las 'buenas razones' científicas como si fuese necesario probar cueste lo que cueste, cuando a veces carecemos de pruebas y la persuasión es mayor que la demostración? Esta limpieza se aferra de hecho a una exigencia interior, íntima, difícil de formular en un primer tiempo, pues puede parecer muy gratuita, lavar sistemáticamente lo que no se ve, fuera de todo 'olor' y de toda 'mugre' es exigencia que no nace de la ciencia sino del código social... Al principio la ciencia sirve de relevo a estas conminaciones, cuyas razones se sienten más que se explican, pero al mismo tiempo refleja y refuerza su certidumbre y sirve para objetivar más la norma y para transmitirla...» (1991: 264).

La importancia ganada sobre el posible perjuicio de la salud, de los riesgos que sobrevendrían si no se respetaban ciertas pautas de cuidado médico, sólo se relativizarán cuando la pauta esté definitivamente internalizada ${ }^{6}$. Como observa nuevamente Vigarello: «...A mediados del siglo XIX estos preceptos, reconocidos desde hace tiempo, se van desdramatizando y revelan otras vertientes más ocultas (...) Es posible proporcionar la prueba de que un sujeto que se lava muy poco puede seguir en perfecto estado de salud y no presentar más que algunas molestias locales sin gravedad. Pero parece que se pueda admitir 1- que hay una necesidad de limpieza, aunque más no fuera a causa del olor

\footnotetext{
${ }^{6}$ También en su sociología de las costumbres, Elías notaba las distintas utilidades de la medicina en relación a las costumbres. En su estudio del manual de Erasmo refería: «...No se encuentran muchas justificaciones por razones de salud en esta obra erasmiana y cuando se encuentran son, precisamente, para evitar las coacciones y las exigencias de la represión, mientras que más tarde, en el siglo XIX, sirven casi siempre para conseguir la moderación y la renuncia a los impulsos. De nuevo en el siglo XX aparece aquí un ligero cambio...» (1993: 177).
} 
desagradable y del aspecto que presentan los individuos sucios, 2- que además el psiquismo queda influido por la limpieza corporal, 3- que, finalmente, esta imposición cotidiana del aseo del cuerpo forma parte de estas disciplinas favorables a una educación de la voluntad, útil para un buen equilibrio (...) El higienista de 1950 explica ahora con argumentos psicológicos y sociales ciertos comportamientos que datan de fines de siglo y que pretendían obedecer en prioridad a pruebas fisiológicas. Y dice lo que no podía formularse en aquel entonces, pues las prácticas parecían promover imperceptibles puntos de referencia...» (1991: 275).

Retornando al objeto que nos ocupa, parte de la historia de la psiquiatría revela también la constitución del manicomio como un laboratorio de prácticas, en donde casi necesariamente la persuasión es mayor que la demostración, y en donde se registra la sucesión de una serie de ortopedias para corregir los comportamientos y sobre todo para corregir al cuerpo. La preocupación por la limpieza, por la alimentación, por el comportamiento en público, por el tratamiento de las necesidades, para las contaminaciones y la degeneración, produjeron toda una serie de técnicas de administración, como los chalecos, las duchas, el aislamiento, la vigilancia panóptica.

Recordemos con Foucault: «...Son los instrumentos que podríamos llamar ortopédicos, me refiero con ello a los útiles cuya función no es la marcación del poder, el arrancamiento de la verdad, la garantía, sino el enderezamiento y el adiestramiento del cuerpo. $Y$ me parece que esos aparatos se caracterizan de la siguiente manera. En primer lugar, son aparatos de acción continua. Segundo, son aparatos cuyo efecto progresivo debe consistir en hacerlos inútiles, es decir, en última instancia, debemos tener la posibilidad de retirar el aparato y que el efecto logrado gracias a él esté definitivamente inscripto en el cuerpo. Por lo tanto, aparatos de efectos de autoanulación. Y, para terminar, en la medida de lo posible, aparatos homeostáticos, cuanto menos resistencia se le opone, menos se los siente; a la inversa, cuanto más se intenta escapar a ellos, mayor es el sufrimiento. Es el sistema del collar con puntas de hierro, o el sistema de la camisa de fuerza, cuando más nos debatimos más nos estrangulamos; o el sistema del sillón que provoca vértigo, mientras no nos movemos, estamos convenientemente sentados; en cambio si nos agitamos, la trepidación del sillón nos marea...» (2005: 131).

Ortopedias de regulación, ortopedias de fijación en las costumbres, recordemos aquello de que todo documento de civilización es un documento de barbarie ${ }^{7}$.

¿Qué queremos decir con ésto? Que la crítica de las antiguas formas debe ser realizada desde una historia del presente, no para naturalizar sino para comprender el por qué de ciertas prácticas ${ }^{8}$. Es decir, estamos lejos -aunque, como lo evidencia cada tanto la crónica periodística en los manicomios, no tanto- de este tipo de ortopedias y de formas «primitivas» del tratamiento moral.

\footnotetext{
${ }^{7}$ El derrumbe civilizatorio de los manicomios (la segregación de las personas locas, su disciplinamiento, su minorización filantrópica) podríamos entenderlo como parte de las consecuencias casi necesarias del proyecto alienista o, como muchas veces la psiquiatría defiende, como parte de sus desviaciones.

${ }^{8}$ No revisaremos en este trabajo las distintas reformas de la psiquiatría y su evolución «dinámica» en las ortopedias más tutelares para la fijación de los comportamientos, ni tampoco seguiremos los pasos de su aggiornamiento en detalle en la administración del problema de la locura y de sus límites en la comprensión de la misma.
} 
Estamos lejos del control social insistente sobre ciertos comportamientos «extravagantes».

Si volviéramos por unos instantes a la historia de los buenos modales y las costumbres, encontraríamos enseguida las criticas roussonianas a la representación y a las técnicas de etiqueta aristocráticas, el rechazo de la burguesía a las formas amaneradas de conducirse en la vida social y crítica a las formas teatrales de la cortesía. Revel sintetiza parte de la devaluación de este código de comportamientos y no hace sino reafirmar el planteo de Elías de que el mismo está devaluado porque ya sus recomendaciones están ancladas en la segunda naturaleza de la personalidad moderna: «...La doctrina de la civilidad se extiende por todas partes, pero en ese momento ya no es más que un vestigio. Estancado, empobrecido, descalificado, desgastado por sus propias contradicciones, el proyecto de reconocimiento que debería haber permitido la construcción de una sociabilidad regulada ya sólo sugiere normas autoritarias y una comedia de las apariencias a las que el vulgo tiene la debilidad de conceder algún cierto crédito. Antes que se hayan impuesto nuevos códigos de comportamientos colectivos la civilidad hace un pobre papel frente al triunfo provisional del individuo y de su irreductible espontaneidad. El texto que durante siglos pretendió enseñar a los niños se ha convertido en el símbolo por excelencia de una inadaptación, el sueño del gobierno del alma termina en una gesticulación irrisoria. La civilidad es lo que queda cuando uno no ha aprendido nada...» (1990: 207).

\section{Los usos de la civilidad en los manicomios líquidos y las derivas del comportamiento bizarro}

Pero hoy, como ya dijimos, no estamos en tiempos de la hegemonía de las formas más custodiales del control de las costumbres de la psiquiatría, sino que nos confrontamos con una crisis de las prácticas correctivas. Los nuevos (viejos) discursos sobre la locura, exigen una mayor sensibilidad por su especificidad y se añade una terapéutica más preocupada por su autonomía. Estamos en tiempos de la desregulación de ciertas prácticas y en alguna medida frente a un nuevo elogio de la locura ${ }^{9}$. Ahora, paralelamente, nos podríamos hacer la pregunta de cómo están funcionando esas barreras culturales, esas distancias, tanto en el interior como en el exterior de los asilos; cómo están funcionando las costumbres y los códigos de convivencia en el asilo y en la vida social.

En primer lugar, podríamos reconocer que el asilo ya no es lo que era, es decir, así como otras instituciones, el manicomio no ha salido indemne de la crítica reconocida en los años '60 (aunque inaugurada mucho antes) y que la

\footnotetext{
${ }^{9}$ «Elogio de la locura», otro de los textos «populares» de Erasmo que se dan cita en este trabajo, para ampliar las ambiguas relaciones entre la locura y las buenas costumbres. Texto que desde el comienzo apela a la razón irónica, ya que su nombre en latín Moriae encomium tiene un fuerte aire de familia con el apellido de aquél a quien está dedicado el texto, el Humanista Tomás Moro. En este clásico texto humanista, Erasmo utiliza la locura como punto de partida para cuestionar las formas y jerarquías sociales, para desenmascarar las hipocresías. En su elogio de la locura hace que la locura misma sea quien hable y desenmascare estrato por estrato la sociedad de su tiempo. La locura será locura, pero tiene derechos y elementos para que su alegato sea escuchado.
} 
sociología crítica no ha dejado de registrar. Asistimos a un largo trabajo de desencantamiento de estas instituciones, al desencantamiento con el sistema disciplinar, que ahora parece reducirse a una función soft de control social, a la mala fe de la institución. Incluso cuando hoy se observa cierto retorno con la obsesión antropológica de la seguridad, la misma es ampliamente reducida a una resistencia contra la crisis, a una técnica de control de los riesgos, a una preservación de mínimos niveles de convivencia institucional. La disciplina hoy es un problema, ya que quienes la ponen en práctica como quienes se «benefician» deberían percibirla como justa.

Institución problema, enfermedad institución como decía el viejo Basaglia, nos lleva a otra discusión que queremos introducir para volver luego sobre una sociología de lo cotidiano de las costumbres asilares. Este planteo quiere funcionar a manera de disparador, como se decía hace unos años en los ejercicios de análisis institucional, para movilizar una serie de discusiones, en este caso, lo que podríamos sintetizar como el debate antimanicomial. Ya que nombramos debate, nos interesa pensarlo -como refiere Zigmunt Bauman (2001: 38)- en el sentido del ágora y de la reconstrucción de lo público, ese espacio en el que los problemas locales, parciales, se reúnen de manera significativa, es decir, no sólo para provocar placeres narcisistas ni en procura de lograr alguna terapia mediante la exhibición pública, sino para buscar palancas que, colectivamente aplicadas, resulten suficientemente poderosas como para elevar a los individuos de sus desdichas individuales. El espacio donde pueden nacer y cobrar forma preguntas tales como: ¿La necesidad de qué tipo de instituciones «democráticas y públicas» -y agregaríamos no disciplinarias o cuasi medievales- para los hombres infames? ¿Qué tipo de instituciones para los hombres infames ${ }^{10}$ ? ¿Qué tipo de código de convivencia urbano? Creemos que el esfuerzo de este trabajo es entrar por un lugar marginal a las discusiones antimanicomiales, qué hacemos con la limpieza, qué hacemos con la comida, qué hacemos con el devenir público del loco en la ciudad, no como voluntad de poder sino como control de nuestras propias prácticas.

Volviendo sobre otras escenas del olor manicomial, recordamos algunas especialmente tragicómicas en el gobierno de las costumbres actuales: una reconocida médica psiquiatra, le manifiesta a un paciente que no lo va a atender si no se baña. Otra escena con respecto a los olores, un paciente con

${ }^{10}$ Hombres infames, utlizado varias veces en el texto, es un guiño a Foucault y una forma literaria de no caer en las estructuras y nosografías entre tutelares y peligrosistas. Pero también quiere situar que el desafío de atención a los locos e indigentes que necesitan acompañamiento regular en la perspectiva de asistencia en la comunidad, exige replantear ampliamente el debate sobre la producción de cuidados y de la solidaridad en la sociedad contemporánea, marcada por la sociedad de mercado, el individualismo, la competición, la cultura del consumo, la crisis de los programas sociales estatales, la violencia en el espacio público, el desempleo estructural y el desprecio presente hacia los grupos «desviantes». La cuestión es particularmente grave en la producción de cuidados y asistencia a los usuarios y sus familiares, ya que los modelos convencionales de familia con los que opera la clínica médica de familia se van desestructurando y la capacidad de producir cuidados en su ámbito disminuye. Por eso se hace central en las discusiones sobre desmanicomialización el tema de que el manicomio deje de ser la política social obligada para las personas locas; en que las lógicas de relegación de otras instituciones comunitarias, sanitarias y sociales en un juego de empuja-empuja derivan a los manicomios, reproduciendo el estigma y la desvaloración social de los usuarios. Es decir, la ideología de la exclusión, la que segrega, encierra y custodia al enfermo mental, no es monopolio de la psiquiatría, forma parte de las barreras sociales más comunes de la población, activada muy especialmente en estos tiempos conservadores de disolución social, en el que el racismo anti-loco nunca está totalmente a la «retaguardia», a pesar de las «vanguardias» multiculturalistas. 
algunos kilos de más llega de su tapera del asentamiento con varios días sin bañarse al centro de día, la portera, que es una experta en las formas del buen trato, le permite pasar y renglón seguido apela al desodorante de ambientes en forma obsesiva.

Además, recordemos que los usos de la civilidad son una de las primeras baterías que utiliza cualquier estudiante de ciencias sociales para sostener su crítica al manicomio, el comedero de los pacientes, el no cuidado con el control de esfínteres y el abandono del aseo, la falta de privacidad e intimidad, el ocio y el cigarrillo de forma compulsiva, las personas desnudas o vestidas con varios pulóveres en pleno verano. ¿Por qué recordamos esto?, por lo ambiguo de las relaciones entre la locura y la institución, entre los usos de la civilidad y la humanización de la asistencia.

Esta es una de las paradojas, cuáles son las soluciones que se vienen ensayando para estos problemas. Si por un lado hay mayor tolerancia y una de las tantas muestras es que el elogio de lo bizarro, lo raro, lo extravagante, lo insólito ha pasado de la calle al arte y del arte a la calle, por otro lado encontramos que el temor antiloco y su potencial disruptivo de ciertas costumbres, no está totalmente demode, y lo preocupante vuelve en estas clásicas viñetas clínicas: «Alejandro es un joven de 26 años. Es conducido al Hospital (su cuarta internación) por su madre y por su hermana. Se encuentra vestido con una remera de mangas cortas y ojotas (a pesar de que es invierno). Lleva también patentes de perro colgando en el cuello. Camina con exagerado movimiento de caderas y con pasos excesivamente largos. Su madre dice que Alejandro ha dejado de tomar la medicación desde hace un mes y que se comporta de manera extraña. El paciente ha salido numerosas veces desnudo a la calle y ha comido papel. Su discurso presenta hiperprosodia y paralogismos...».

Ahora, entre lo dicho y lo hecho, cómo asilamos a Alejandro, cómo calificamos sus conductas, cómo acompañamos al mismo en su historia asistencial. Tres líneas -siendo muy esquemáticos y siguiendo fundamentalmente a Pavarini- se vienen configurando dentro de la «nueva» psiquiatría o la despsiquiatrización de los modelos asistenciales y cada una de ellas tendría particulares implicancias para la comprensión de la situación de Alejandro:

A- la más pasteuriana, que retorna como especialización de la medicina y que se ancla en definiciones clásicas de un nuevo positivismo médico y no rompe con el modelo de la psiquiatría tradicional. Como describe Mássimo Pavarini: «En esta dirección, se reivindica la máxima de la medicalización de la psiquiatría, claramente expresada por el último repertorio diagnóstico internacional que continúa realizando una atribución 'objetiva' de patologías a determinadas combinaciones de condiciones. Sin embargo, el mismo DSM advierte que existen 'condiciones que requieren atención o tratamiento pero que no son atribuibles a un disturbio mental como el comportamiento anti-social o la no colaboración con el tratamiento'. Aún cuando reivindicando un rigor médico, la psiquiatría debe renunciar a una diagnosis patológica, perpetúa intervenciones sobre situaciones problemáticas ahora privadas de identidad terapéutica. Por lo tanto, también la medicalización extrema es practicada como una forma de control social extremo y más aún el hospital (la internación se produce en la mayor parte de los casos coactivamente) y los fármacos (a menudo contención química de los excesos). Estas posturas, por ende, con fórmulas más refinadas, no hacen más que enfatizar el estatuto originario de la psiquiatría como 
ciencia médica y práctica custodial...» (1999: 101).

B- la más filantrópica, que retorna como medicina no tanto de los controles sino como medicina social, preocupada por la solución sanitaria de los problemas del déficit social y sostenida en una concepción más socio-genética de la enfermedad mental. Como refiere Pavarini: «No se puede negar que aún está lejos de morir el mito de la inexistencia de la enfermedad mental como estado de patología individual y la asimilación de quien padece el sufrimiento a quien sufre la marginación social. La psiquiatría se transforma así en ayuda y se articula y expresa a través de los servicios sociales territoriales. Finalmente, da voz a su alma filantrópica que recién ahora puede abandonar la custodia para encontrar un espacio real fuera de los manicomios. Los psiquiatras han reconocido desde hace tiempo la cronicidad generada por el manicomio y la 'terapeuticidad' del tratamiento del loco en su medio ambiente social hasta alimentar ciertas dudas acerca de la utilidad del tratamiento manicomial...» (1999: 102).

C- la más liberal, que en nombre del rechazo de la tutela y la minorización de las personas locas, aboga por el retorno de los contratos asistenciales y el liberalismo terapéutico pero, como ya diría Durkheim, no todo está escrito en el contrato: «...Una fuga que Ilamaremos 'elitista' hacia la asimilaciónhomogeneización de la psiquiatría a los estatutos de las profesiones liberales (...) En esta dirección la psiquiatría se hace palabra y se refiere al paradigma analítico; el tratamiento se propone la 'liberación' del paciente a través de la 'escucha' y la 'interpretación' del conjunto de experiencias que se encuentran presentes en la conciencia individual del mismo. Si esto parece ser lo contrario del control y la normatización tradicionalmente ofrecidos por la psiquiatría, en la sustancia no hace otra cosa que perpetuar la realidad social problemática que se encuentra en la base del malestar psiquico, dado que no la afronta como tal sino que se limita a interpretar el modo en que es subjetivamente vivida. El médico se aggiorna como especialista de la escucha de un cierto conjunto de experiencias y sensaciones del paciente; no son pertinentes para su interpretación 'elementos determinantes de la situación' y esto reproduce 'una ideología de la sustitución' que desplaza el impacto del problema, según la mejor tradición histórica de la medicina...» (1999: 103).

Modelos asistenciales que aquí sólo quieren funcionar a manera de los tipos ideales weberianos, para entender cómo los comportamientos bizarros, los comportamientos antisociales pueden ser medicados, sancionados, regulados, escuchados y gestionados en nuestras nuevas instituciones psiquiátricas. También que el retorno del profesionalismo, con sus diversas éticas protestantes y de las otras, son particularmente sordas a un diálogo con la locura y sobre todo a plantearse el problema de la hospitalidad en instituciones marcadas por la hostilidad; en donde el repliegue en lo profesional ${ }^{11}$ alimenta una

${ }^{11}$ Profesionalización que, por otro lado, es parte de la dinámica normal de nuestras sociedades, como analiza Chartier en sus trabajos sobre Elías: «...El contrapunto de la sociedad cortesana es la sociedad burguesa de los siglos XIX y XX, de la cual difiere por la ética económica, la actividad profesional de sus miembros, la constitución de una esfera de lo privado separada de la existencia social. Las divisiones hoy consideradas evidentes (por ejemplo, entre vida pública y vida privada), las conductas consideradas como únicas, posibles y racionales (por ejemplo, el ajuste de los gastos familiares a los ingresos disponibles), pueden así verse desprovistas de su supuesta universalidad y ser llevadas al estatuto de formas temporalmente circunscriptas, segregadas por un equilibrio social nuevo que no era el de las sociedades cortesanas...» (1995: 84). 
serie de barreras culturales en que la prudencia replica una distancia que se sigue clasificando dentro del orden de lo llamativo en la psicosis. Como diría en un lenguaje neutral y descriptivo un reconocido profesor de psiquiatría: «...el conjunto de conductas que desde la perspectiva del enfermo mantiene total coherencia con sus procesos mentales, pero que chocan frontalmente con pautas sociales relativamente primarias de comportamiento: hablar solo, cantar, gritar, desvestirse, etc.». Y cuando se terminan los comportamientos bizarros y las conductas antisociales, con los controles farmacológicos, nuestra sensibilidad, nuestra civilidad ${ }^{12}$, se choca con otra forma de distanciamiento. El loco debidamente cronificado por la medicación afecta nuestra sensibilidad, extrañando al paciente delirante y disruptivo que ahora encontramos encorvado, babeando, adaptado y le preguntamos -otra vez nos provoca malestar- por qué no se puede mantener sentado en su silla para poder así continuar la entrevista.

Para decirlo a martillazos, debemos preguntarnos si ciertos profesionales psi, marcados por sus convenciones, sus problemas de etiqueta, su rechazo a la pérdida de la compostura, sus delegaciones y sus límites, están en condiciones de acompañar las rupturas con el racismo anti-loco presente en algunas de las pautas culturales interiorizadas por el vulgo y la intolerancia selectiva a ciertas prácticas culturales «primarias» presentes en las instituciones y en las comunidades. El que no tiene «tela» puede llegar a ser escuchado?, lo socio cultural no corre el riesgo de encerrarse en una estructura y en una compasión cruel?, sobre todo si hace uso de estrategias de sobrevivencia y de interpelación de los modelos asistenciales: «...es un perverso, es un manipulador...», suele ser escuchado en la terminología psiquiátrica más pura. El modelo profesionalista de servicios para el caso de la locura es para recuperar un concepto clásico, iatrogénico, como refiere Diana de Mauri: «su principio organizativo fundamental es la prestación del especialista, que se distribuye con criterios de derecho y a través de relaciones de tipo contractual o que querrían serlo. Pero estas relaciones siguen siendo fuertemente asimétricas: '...por una parte, hay alguien que tiene una necesidad, un problema, un padecimiento más o menos grave y urgente, y por otro hay alguien que detenta el poder saber de responderle, por una parte hay alguien que detenta el código para definir esa necesidad, por otra parte hay alguien que si quiere encontrar una respuesta, debe saber, poder y querer expresarlo y aún sentirlo en ese código. Por lo tanto en este dispositivo la dependencia no desaparece, se transforma en lealtad y sumisión al orden del discurso y a las expectativas de comportamiento del servicio...» (1997: 29).

Unas páginas atrás, apelando a cierta memoria social reciente, hablábamos de código de convivencia urbana ${ }^{13}$, sobre todo para pensar qué tipo de

12 En esta parte del texto se perderá la precisión conceptual para utilizar casi arbitrariamente algunos conceptos en su polivalencia estratégica, en especial los de civilidad, cortesía y hospitalidad.

${ }^{13}$ Nos referimos a los debates en torno a la derogación de los edictos policiales en la ciudad de Buenos Aires. Estos códigos eran una de las herramientas ya en desudo de todo tipo de criminalización de las costumbres, que la simplificación de los medios y su política espectáculo redujo como el problema de las zonas rojas y la exhibición «impúdica» de los travestis. Las propuestas alternativas a este código y las discusiones con los vecinos, fueron un nuevo ring side de la lucha entre progresistas y conservadores a la que nos tiene acostumbrados la primera ciudad del país. Mientras tanto, como sintetizó lúcidamente Zaffaroni, preocupados por el sexo de los travestis, sucedió lo de Cromagñon, problema de un Estado ausente y de la falta de «otros» controles del que el conservadurismo liberal de los ' 90 no quiere hacerse cargo, y que, por otro lado, son centrales para la convivencia urbana. 
pautas de convivencia justas se pueden ensayar en nuestras instituciones; sobre todo para desnaturalizar las expectativas de comportamiento que tienen los «enfermeros», por ejemplo, ya que se dedican a gerenciar lo cotidiano, con respecto a los pacientes, y también para reconocer cuáles son las exigencias de civilidad que los propios pacientes plantean, por fuera y por dentro de las rutinas clínicas, más acá y más allá de sus comportamientos bizarros.

Demos otro tiempo a la descripción de algunas situaciones cotidianas, con reconocidos ecos goffmanianos ${ }^{14}$, en que tanto el personal de enfermería como los pacientes se encuentran con pautas de comportamiento que no crearon pero que tampoco pueden cambiar. A poco de entrar y apenas «pasada» la crisis, el paciente nota que se le impone un modo de vida en una organización que quiere mantener sus pautas y reglamentos médicos. Es confrontado a todo un conjunto de gestos de la vida cotidiana en el hospital, debe adaptarse a las horas de las comidas, al control de las visitas, a mantener su higiene y su autocuidado, a convivir con viejos pensionistas y nuevos pacientes, a distinguir las jerarquías y las formas, a quién le puede demandar qué (a las enfermeras, a los residentes, a los equipos). En suma, para no ser maltratado en exceso debe aprehender un rol y no faltarán entre los crónicos quienes lo alerten y ejerzan ciertos controles sobre las desviaciones permitidas y no permitidas también para un loco en crisis.

Por un lado, los enfermos a veces también critican las condiciones de vida institucional y exigen otras pautas de cuidado, de hospitalidad, en conclusión, de civilidad y cortesía: la calidad de las comidas, las exigencias de silencio o los ruidos excesivos, el aburrimiento y el ocio de la invalidación, las visitas de médico y las terapias brevísimas, las puertas abiertas o cerradas sin precauciones, la sobremedicación, el encierro, la no intimidad o privacidad. Por otro lado, enfermería suele quejarse de los enfermos, de sus exigencias y de su actitud querellante, de su impaciencia, de su falta de higiene personal, del abandono o de la invasión de las familias, de su sexualidad o de su «hospitalismo», de su sumisión demasiado pasiva a las constricciones de la vida institucional $Y$ también otra queja crónica, sobre la permisividad de los «profesionales» al simplemente dejarles el trabajo sucio en relación a las pautas de convivencia o a la administración de los conflictos -poner orden- para después acusarlos de «autoritarios». En cuanto a las conductas a reprobar para cualquiera de los actores institucionales (enfermeros, psicólogos, psiquiatras, talleristas, pacientes): demasiado activo e interpelador, es desestabilizador, demasiado pasivo y burocratizado, lo es en igual forma, cíclicamente se van ocupando los lugares; a falta de energias productivas que renueven las prácticas asistenciales y la idea de trabajo bien hecho, instalando todo tipo de prácticas defensivas y de formas de desobediencia funcionales a la pervivencia del manicomio.

Las direcciones de las instituciones, frente a estos reclamos de civilidad y a la guerra de trincheras, optan la mayoría de las veces por administrar la crisis. En la medida de lo posible, se administra con un plus de posibilismo y otro de laissez faire, ya que fundamentalmente también estas instituciones están preocupadas por administrar su sobre-vivencia, sin controles políticos salvo los

${ }^{14}$ En la medida que se va realizando este trabajo, se observa la necesidad de nuevos estudios al estilo de Erving Goffman y sus clásicos estudios sobre lo cotidiano de los manicomios sólidos, ese estudio de la sociedad moderna en recipiente cerrado, como lo calificaba Robert Castel a manera de reconocimiento. 
contables, sin evaluación de la calidad de las prácticas asistenciales. La autonomía de los distintos espacios institucionales acentúa tan sólo la lógica de los feudos, y se permite el desarrollo de cierta permisividad en las pautas de convivencia, en donde a nadie mayormente se le cobre por sus responsabilidades.

Pero también, cuando esto no es suficiente o cuando las zonas de tierra de nadie aumentan, se recuperan según la coyuntura pedagogías de la sociabilidad de retorno de la autoridad, con la reposición de prácticas represivas y de control de los comportamientos, con algún parecido de familia con prácticas conservadoras de otras políticas de seguridad, como la tolerancia cero. Es decir, la apelación al regreso a la autoridad tiene cierta oportunidad de seguir siendo un manejo encantatorio de la crisis, «reconociendo» las virtudes del pasado, pero sabiendo que esta solución es pasajera, primero por su mala prensa y, segundo, porque la restauración de la autoridad médica strictu sensu obliga al retroceso considerable de los derechos de los pacientes a no sufrir en silencio las formas más exigentes de criminalización de las costumbres.

Y, last but not least, para hacer justicia a la antipsiquiatría y a la desmanicomialización, toda una serie de micropolíticas que se viene sosteniendo desde la marginalidad presupuestaria y la militancia, juegan a la reposición de esa cercanía de hecho esperando los avances del derecho y cierta cultura democrática en estas instituciones y servicios. Este «elogio de la locura» -que promueve aquella figura de la poesía de Caetano «de cerca nadie es normal»-, está fundamentalmente preocupado por una política de validación y de inversión del estigma, en que las instituciones de la violencia o su reverso, la tolerancia, se confronten con la exigencia de respeto a la locura y del derecho a la ciudad.

Decíamos micro políticas que están tornando la institución y la ciudad (sólo por algunas horas) a veces más hospitalarias; en las que, volviendo sobre el tema de las convenciones sociales como la comida, el aseo personal, la limpieza, el baño, la exposición y presentación en público, están generando ortopedias sociales, en nombre del derecho de los «locos» a una vida «normal». Pasan por nuestras cabezas los programas de radio en que la libre expresión pone en crisis el no ha lugar al que la justicia y la psiquiatría condenan muchas veces los argumentos de los pacientes o la tutela de los aburridos talleres de la tarde de los hospitales; un taller de peluquería en medio de un hospital psiquiatrico que se monta para salir del autoritarismo higienista pero también para promover un cuidado de sí con derecho a tintura; la Cooperativa que rechaza el pecunio como forma tipica de intercambio de favores en el Hospital y devuelve cierta experiencia de negar el ocio y hacer negocios, sin apelar a las tutelas de la laborterapia; la asamblea de usuarios que reclama la reglamentación de la ley de salud mental y paradojalmente reclama más orden en el Hospital frente a la presencia de nuevos inquilinos socializados en experiencias de convivencia más carcelarias; las salidas «terapéuticas» con la ocupación de espacios públicos de convivencia dispersa, en donde la extravagancia y las formas de participación se tornan entre cómicas y patéticas por las transacciones y comunicaciones distorsionadas con la gente normal ${ }^{15}$. O también,

${ }^{15}$ Nos viene a la memoria la difusión de la película «Los Idiotas» en un curso de capacitación hecho en el psiquiátrico, como forma no holywoodense de incentivar los acompañamientos terapéuticos y las salidas de ocupación grupal. 
cansados de cierta interiorización de pautas de higiene, es convocado el personal de mantenimiento a arreglar el baño del paciente, que hasta ahora es sólo repelido con desodorantes de ambientes. O que en un loco taller de cocina, se leyeron las recomendaciones de Leonardo Da Vinci para conducirse en la mesa, eso sí, sin servilletas a la vista, la gran invención de Leonardo.

Elogio de la locura, que al participar de una crítica de las costumbres de la cultura de las instituciones y de la cultura asistencial, repone la «creencia» de que los comportamientos de los locos se confrontan al de los normales como una especie de corredor de espejos, que cuando comparamos los comportamientos del «insano» con los de la sociedad y la cultura, vemos dos facetas, dos expresiones, dos rostros, cada uno cuestionando al otro.

Si la normalidad condena a la locura por irracional, por excesiva ${ }^{16}$, por perversa, por agresiva, la locura casi responde con la misma moneda, el loco resalta la hipocresía, los comportamientos «burocráticos», las formas autoritarias de pacificación de las costumbres, las etiquetas profesionales, la violencia simbólica de las instituciones. Y también el comportamiento bizarro, si es leído atentamente, denota claramente, en forma desviante o no convencional ${ }^{17}$, las ideas, valores, aspiraciones y miedos de sus contemporáneos, como aquel paciente que en estos últimos días refería no querer irse del manicomio por la ola de inseguridad.

Cuando leemos las conductas desviantes de los locos de los sectores populares, tenemos una visión ampliada de aquello que puede ser pensado en el sentido de un universo al margen. Podemos comparar eso al modo como Goffman aconsejaba poner en crisis el «exotismo» o la «extranjeridad» antropológica del loco, ya que tradicionalmente nos venimos interesando en todo lo que hace diferentes a los habitantes del manicomio público con los sectores populares, sin ver todo lo que tienen en común con las clases sociales subalternas: la lucha por la sobrevivencia, la crisis de las formas de protección familiar, la ética picaresca y las necesidades de ilegalismo de la mayoría desviante, la pobreza intensa y la desocupación frente a un Estado desertor.

Finalmente, para concluir, el año pasado de viaje por Rosario, un reconocido líder anti-manicomial brasilero en medio de una de sus charlas en el psiquiátrico, decía que un analizador práctico de la humanización de la asistencia, era desterrar del ámbito institucional ese olor manicomial, ese «olor» tan característico de los olores de los baños, de los comedores, de la ropería de los manicomios.

\footnotetext{
${ }^{16}$ Zigmunt Bauman en uno de sus textos sobre la ética posmoderna refiere: «...El más universal de nuestros eslóganes es sin exceso. Vivimos en la era del individualismo más puro y de la búsqueda de la buena vida, limitada solamente por la exigencia de tolerancia (siempre y cuando

vaya acompañada de un individualismo autocelebratorio y sin escrúpulos, la tolerancia sólo puede expresarse cómo indiferencia...» (2001).

${ }^{17}$ Como refiere Chartier en su lectura de Elías: «De aquí surge la posibilidad de dejar atrás la oposición entre el hombre considerado como individuo libre y sujeto singular, y el hombre considerado como ser en sociedad, integrado en solidaridades y comunidades múltiples. De aquí surge también una forma de pensar las relaciones intersubjetivas, no con categorías psicológicas que las suponen invariables y consustanciales con la naturaleza humana sino en sus modalidades variables desde el punto de vista histórico, directamente dependientes de las exigencias propias de cada formación social...» (1995: 89).
} 


\section{Bibliografía}

ALTAMIRANO, C. Términos críticos de sociología de la cultura. Buenos Aires, Paidós, 2002.

BAUMAN, Z. En búsqueda de la política. México DF, FCE, 2001.

BURKE, P. Formas de la historia cultural. Madrid, Alianza, 2000.

CASTRO, E. El vocabulario de Michel Foucault. Bernal, UNQ, 2004.

CHARTIER, R. El mundo como representación. Estudios sobre Historia Cultural. Barcelona, Gedisa, 1995.

ELÍAS, N. El proceso de civilización. México, FCE, 1989.

FOUCAULT, M. El Poder Psiquiátrico. Buenos Aires, FCE, 2005.

FOUCAULT, M. Los Anormales. Buenos Aires, FCE, 2000.

FOUCAULT, M. Defender la Sociedad, FCE, 2000.

GALENDE, E. El Sufrimiento Mental, el poder, la ley y los derechos. Buenos Aires, Lugar Editorial, 2006.

GAUCHET, M. La Practique del espiritu humain. La institution asilaire et la revolution democrátique. París, Gallimard,1980.

GOFFMAN, E. Asilos, estudios sobre la condición social de los enfermos mentales. Buenos Aires, Amorrortu, 1970.

GOFFMAN, E. Estigma, los usos sociales del handicap. Buenos Aires, Gedisa, 1988.

HOURCADE, E (comps.) Luz y contra luz de una historia antropológica. Buenos Aires, Biblos, 1995.

GUATTARÍ, F. Las tres ecologías. Valencia, Pre-Textos, 1991.

PAVARINI, M. «La tutela social de la/ a la locura. Notas teóricas sobre la ciencia y la práctica psiquiátricas frente a las nuevas estrategias de control social», en revista: Delito y Sociedad, Buenos Aires, 1999.

REVEL, J. «Los usos de la civilidad», en: Historia de la vida privada, Taurus, 1990.

VIGARELLO, G. Corregir el cuerpo. Historia de un poder pedagógico. Buenos Aires, Nueva Visión, 2005.

VIGARELLO, G. Lo limpio y lo sucio. La higiene del cuerpo desde la Edad Media. Madrid, Alianza, 1991. 